\title{
GESTÃO AMBIENTAL: UM ESTUDO EM EMPRESAS DO SETOR SUCROALCOOLEIRO EM GOIÁS
}

\author{
ENVIRONMENTAL MANAGEMENT: A STUDY ON ETHANOL SECTOR COMPANIES \\ IN GOIÁS
}

Recebido em 04.03.2013. Aprovado em 10.09.2013

Avaliado pelo sistema double blind review

DOI:http://dx.doi.org/10.12712/rpca.v7i3.264

\begin{abstract}
Marta Cleia Ferreira
marta.cleia@hotmail.com

Curso de Administração da Faculdade de Ciências e Educação de Rubiataba - Rubiataba - GO - Brasil.
\end{abstract}

\begin{abstract}
Resumo
O setor empresarial vem promovendo uma mudança em seu modelo de gestão, desde o início dos anos de 1990, quando assumiu uma atitude positiva para com o meio ambiente. Assim, as questões ambientais têm se tornado parte do planejamento estratégico das organizações devido às regulamentações mais rigorosas e às demandas da sociedade por uma maior responsabilidade ambiental. Para tanto, este estudo teve como objetivos identificar e analisar as práticas ambientais adotadas pelas empresas do setor sucroalcooleiro em Goiás e procurar respostas para questões relacionadas aos fatores que possam contribuir para a criação de vantagens competitivas dentro dessas organizações. As organizações enfocadas no estudo são denominadas A, B, C e D. Esta pesquisa utilizou os fundamentos da abordagem qualitativa e exploratória e pode ser caracterizada como uma pesquisa de campo. Na cultura e no processamento da cana-de-açúcar, certamente ainda se fazem presentes impactos negativos para o meio ambiente. Contudo, a adoção de ações aqui mencionadas, como a busca pela conservação do solo e da vegetação, a troca da queimada por colheitadeiras, a racionalização no uso de produtos químicos, o reaproveitamento de resíduos do processo produtivo (como a geração de energia através do bagaço da cana), dentre outras, apontam benefícios para as empresas do setor e para o meio ambiente.
\end{abstract}

Palavras-chave: Empresa. Práticas. Meio ambiente. Sucroalcooleiro. Goiás.

\begin{abstract}
The business sector is promoting a change in its management model, since the early 90 s, when it took a positive attitude toward the environment. Thus, environmental issues have become part of the strategic planning of organizations due to stricter regulations and to society's demands for greater environmental responsibility. Therefore, this study aims to identify and analyze environmental practices adopted by companies of this sector in Goiás and to seek answers to questions related to the factors that can contribute to the creation of competitive advantages within these organizations. Organizations involved in that study are labeled A, B, C and D. This research has used the fundamentals of qualitative and exploratory approach and it can be characterized as a field research. In the growing and processing of sugar cane, certainly negative impacts to the environment are still present. However, adoption of actions mentioned here, as the search for the conservation of soil and vegetation, replacing the burned by harvesters, the rational use of chemicals, the recycling of waste in the production process (such as power generation through bagasse sugarcane), among others, point out benefits to business sector and the environment.
\end{abstract}

Keywords: Company. Practices. Environment. Sugarcane. Goiás. 


\section{Introdução}

Desde 1990, quando o conceito de desenvolvimento sustentável passou a fazer parte das agendas das empresas, estas têm tentado estabelecer padrões de produção que resultem em produtos e serviços que preservem o meio ambiente. Deste modo, muitas empresas passaram a operar com base em valores ambientais, demonstrando uma nova perspectiva (ABREU, 2001). Presentemente, nota-se que as discussões em torno das questões ambientais têm se intensificado, e as filosofias de operações de algumas empresas mostram preocupações em atender às demandas dos diversos públicos com os quais se relacionam.

No tocante ao setor sucroalcooleiro, assiste-se, atualmente, a um crescente debate sobre as oportunidades de atender à demanda do mercado global com produtos como o etanol e açúcar, produzidos no Brasil. Tal demanda estaria sendo motivada por fatores, como: 0 desenvolvimento da tecnologia flex fulli preocupações com o aquecimento global, fator que favorece o uso de energias alternativas (como o etanol) ao consumo de combustíveis fósseis; instabilidade na oferta mundial de petróleo, dentre outros. Por outro lado, são questionados os possíveis impactos socioambientais advindos do sistema de produção do setor, como: as emissões atmosféricas geradas pelas queimadas dos canaviais, a contaminação das águas e do solo por efluentes, a expansão territorial para áreas de proteção ambiental, a contaminação por agrotóxicos e a erosão do solo. A estes impactos ambientais potenciais acrescentam-se também os aspectos sociais, como as condições de trabalho no campo, entre outros (SANTOS e ALMEIDA, 2007).

Reconhecendo-se a importância que o setor agroempresarial tem para o desenvolvimento socioeconômico, bem como os grandes impactos que pode causar no meio ambiente, este estudo tem como objetivo identificar e analisar as práticas ambientais adotadas pelas empresas do setor sucroalcooleiro em Goiás. Este artigo pretende, também, procurar respostas para questões relacionadas aos fatores que possam contribuir para a criação de vantagens competitivas dentro destas organizações, considerando-se a produção agrícola e industrial. Busca-se compreender, também, se as ações caminham rumo a uma concepção mais próxima ao padrão de desenvolvimento sustentável. Desta maneira, as empresas focadas neste estudo foram denominadas de A, B, C e D, visando resguardar suas imagens.

Além da introdução, o artigo estrutura-se em seis seções que abordam a teoria que sustenta a pesquisa, o panorama do setor enfocado, as práticas e o direcionamento do setor sucroalcooleiro, a metodologia utilizada na investigação, a discussão dos resultados e as considerações finais do estudo.

\section{Gestão ambiental nas organizações e suas potencialidades}

A partir de 1962, com a publicação do livro Silent Spring (Primavera Silenciosa), da bióloga Rachel Carson, iniciou-se um debate mais acentuado sobre a relação entre o homem e o meio ambiente, até então discutido de forma leviana. Várias convenções e acordos foram firmados desde então. Dentre eles, os principais foram: a Conferência de Estocolmo, o informe Brundtland, a Eco-92, Rio+5, Protocolo de Kyoto, Rio+10 e, a mais recente, COP15, em Copenhagen. Todos estes acontecimentos tiveram o intuito de reunir chefes de Estado e procurar alternativas para reduzir as ações nocivas ao meio ambiente, oriundas de um desenvolvimento econômico que tem priorizado o progresso econômico, evocando-se, assim,

\footnotetext{
1 Tecnologia que possibilita o uso de misturas de etanol e gasolina nos veículos.
} 
uma preocupação com a sustentabilidade (MONTEIRO e FERREIRA, 2009). Abreu (2001) afirma que, na Conferência Mundial do Meio Ambiente e Desenvolvimento, conhecida como ECO-92, ficou definido que a preservação do planeta é responsabilidade de todos os países, aceitando-se a necessidade de desenvolvimento, mas com a visão de responsabilidade com as gerações futuras. Como resposta a essas pressões institucionais, surgiram novos modelos organizacionais, vistos como os mais adequados para a era atual, como é o caso das organizações ambientalmente responsáveis.

Diante desse cenário, vale ressaltar que o setor empresarial vem promovendo uma mudança em seu modelo de gestão, desde o início dos anos de 1990, quando assumiu uma atitude positiva para com o meio ambiente, mas não mais por causa da rigidez da legislação ambiental, e sim por vislumbrar oportunidades de negócio ao agregar a variável ambiental em suas estratégias empresariais. De uma postura reativa passou-se para a proativa e, portanto, antecipar-se à legislação ambiental não significaria mais apenas manter ações preventivas para evitar acidentes e riscos ambientais, mas sobretudo obter uma vantagem competitiva (LAYRARGUES, 2000). Walton et al (1998) concordam que as questões ambientais têm se tornado parte do planejamento estratégico das organizações devido às regulamentações mais rigorosas e às demandas da sociedade por maior responsabilidade ambiental. Destarte, entre os objetivos principais perseguidos pelas organizações, incluem-se as ações ligadas ao meio ambiente (DONAIRE, 1994).

Alperstedt et al (2010) consideram que, atualmente, entre os fatores determinantes para a adoção de práticas ambientais de maior relevância para as organizações de qualquer tamanho é, de fato, a pressão da sociedade. A isto se soma a importância das regulamentações governamentais, a adequação aos padrões normativos e a concorrência.

Há autores que argumentam que as empresas da década de 1990 foram condenadas e apresentam-se hoje como convertidas, desejando ser reconhecidas e admiradas por sua excelência ambiental. Atualmente, a imagem de uma empresa preocupada com as questões socioambientais pode ser um grande diferencial (NASCIMENTO, 2007).

Adicionalmente, Barbieri (2004) defende que a abordagem ambiental na empresa pode ser de três tipos. 0 primeiro é denominado de controle da poluição, pois os esforços são direcionados para o cumprimento da legislação ambiental e atendimento das pressões da comunidade. Este tipo mostra-se como uma postura reativa e vinculada, pois é exclusivamente da área produtiva. Por outro lado, as questões ambientais na empresa podem ser preventivas, ou seja, a organização busca utilizar eficientemente os insumos; a preocupação ambiental é mais presente na área manufatureira, mas começou a se expandir para as demais áreas da organização. No último estágio, a questão ambiental se tornou um fator estratégico para a empresa, e as atividades ambientais encontram-se disseminadas pela organização. Assim, percebe-se que a gestão ambiental nas empresas é analisada por estágios evolutivos.

Para Abreu (2001), as empresas com uma conduta ambiental forte têm uma avaliação quantitativa de sua performance ambiental. Por outro lado, as empresas com uma conduta ambiental intermediária estão iniciando o processo, enquanto as empresas de conduta ambiental fraca não praticam medições.

A busca por uma atitude de responsabilidade ambiental corporativa, intensificada a partir da década de 1990, fez surgir um campo de estudo amplo dentro da administração. Estudos nesta área ajudam a entender como os interesses dos dirigentes empresariais pelas questões ambientais são formados e influenciados.

Para Layrargues (2000, p. 82), “todas as corporações empresariais de qualquer porte serão envolvidas nesse processo, simplesmente por se considerar a tecnologia limpa como a vantagem 


\section{GESTÃO AMBIENTAL: UM ESTUDO EM EMPRESAS DO SETOR SUCROALCOOLEIRO EM GOIÁS}

competitiva no cenário comercial contemporâneo". Alguns autores concordam com essa possibilidade ao ressaltar que um comportamento ambientalmente correto por parte das empresas pode trazer benefícios estratégicos, como: melhoria da imagem institucional; renovação da carteira de produtos; aumento da produtividade; melhoria nas relações de trabalho; criatividade para novos desafios e melhoria das relações com os órgãos governamentais, a comunidade e os grupos ambientalistas (CLARO et al, 2008).

Há outro enfoque interessante acerca da responsabilidade ambiental. Alguns autores defendem que, como o mercado se tornou mais competitivo e interligado, as empresas precisam trabalhar em conjunto, procurando rever seus processos de negócio e olhando além de suas fronteiras (WALTON, et al, 1998; SANCHES, 2000). Neste sentido, à luz de uma abordagem ambiental, as empresas devem analisar cada processo ao longo de sua cadeia de suprimentos para identificar as ineficiências que ocorrem.

Muitas empresas que passaram por este exercício e que extrapolam suas fronteiras identificaram processos onde matérias-primas foram desperdiçadas, recursos subutilizados e gastos desnecessários com energia, devido ao uso de equipamentos ineficientes. Por outro lado, rever os processos de compra deve ser o objetivo de qualquer empresa, procurando fazer uma transição para pertencer a uma cadeia de suprimento verde. Tal iniciativa contempla encontrar fornecedores que tenham minimizado seus impactos ambientais, mas sem reduzir a qualidade de seus produtos e sem aumentar os custos (KUSHWAHA, 2010). Essa abordagem possibilita usar os recursos naturais mais eficientemente e melhorar o desempenho ambiental e econômico dos envolvidos (ZHU e COTE, 2004).

Muitos estudos mostram benefícios importantes relacionados às causas ambientais. Sanches (2000, p. 78) defende que "A proteção ambiental passa a fazer parte de seus objetivos de negócios e o meio ambiente não é mais encarado como um adicional de custo, mas como uma possibilidade de lucros, em um quadro de ameaças e oportunidades para a empresa".

Alinhado a essa visão, Segatto-Mendes e Lemos (2007) enfatizam que a redução do impacto ambiental relacionada à produção de bens e produtos está vinculada às estratégias de diferenciação de produtos e pode ter efeitos importantes na renda da empresa por tornar os seus produtos únicos aos olhos dos consumidores. 0 potencial dessas iniciativas na melhoria da reputação da empresa é mais alto do que aquelas dirigidas para processos, pois permite maior visibilidade pública da empresa, atingindo número maior de stakeholders. Por sua natureza, a introdução deste tipo de produto no mercado é geralmente um evento de alta lucratividade.

É importante ressaltar que algumas práticas de produção limpa podem reduzir os custos, bem como abrem possibilidade de vantagens ambientais e competitivas. A lógica dessas práticas de produção consiste em: reduzir, reutilizar, reciclar, reproduzir e recuperar (5Rs). Tratam-se de requisitos básicos para a produção de produtos e serviços de alta qualidade, com pouco ou zero resíduos, possibilitando melhor competitividade dos produtos e serviços (RAHMAN et al., 2009).

Rahman et al. (2009) conduziram uma pesquisa à luz dos conceitos de produção limpa em pequenas e médias empresas (PMEs) na Indonésia. Os autores descobriram que uma empresa alcançou redução de $70 \%$ nos custos de produção, por haver diminuição do retrabalho, resíduos e economia de energia, contribuindo para o meio ambiente. As principais conclusões do estudo mostram que as atividades de produção limpa proporcionam melhoria ambiental e contribuem para a criação de vantagem competitiva em PMEs na Indonésia.

Embora, não existe um consenso se o desempenho social contribui para a determinação do desempenho financeiro ou vice-versa. Mas, os estudos de Coutinho e Macedo-Soares (2002) indicam a existência de uma relação entre as duas performances, indicando que os aspectos 
financeiros e os sociais parecem estar correlacionados positivamente, independentemente de qual delas seja a variável independente.

Nessa linha, os resultados da pesquisa de Machado e Pimenta (2004), buscaram saber se as empresas socialmente responsáveis apresentam desempenho financeiro superior ao de outras organizações que não atendem aos mesmos critérios sociais. As conclusões dos autores sugerem que a adoção de uma postura socialmente responsável pode resultar em uma variedade de comportamentos por parte dos stakeholders, incluindo decisões de compra.

Na mesma perspectiva, sobre a possibilidade de resultados financeiros advindos de um preço superior à comercialização de produtos produzidos em consonância com as normas ambientais, Andrade (2010) afirma que o mercado consumidor brasileiro ainda não exige e pouco valoriza produtos produzidos com respeito aos aspectos socioambientais. Para isso, haveria necessidade de conscientização do consumidor.

Todavia, nota-se que a exigência de lucro e sobrevivência pode conviver harmoniosamente com a responsabilidade ambiental dentro de uma concepção mais ampla, como filosofia de operações da empresa.

\section{O setor sucroalcooleiro no Brasil e em Goiás}

Introduzida no período colonial, a cana-de-açúcar se transformou em uma das principais culturas da economia brasileira. 0 Brasil não é apenas o maior produtor de cana, mas também o primeiro do mundo na produção de açúcar e etanol.

Em comparação a outros países, o Brasil possui uma matriz energética, marcadamente renovável, e foi o principal país do mundo a implantar, em larga escala, um combustível renovável e alternativo ao petróleo. A expansão do mercado mundial de açúcar e Etanol tem estimulado o aumento do investimento no setor em todo o país, que possui grande importância econômica, social e ambiental, sendo grande gerador de ocupação de mão de obra no meio rural com geração de divisas e produção de energia renovável.

De acordo com o PROCANA (2012), o setor possui 8,5 milhões de hectares plantados com a cana-de-açúcar e é atualmente composto por 435 usinas e destilarias (em operação + projetos), apresentando, na safra de 2010/2011, uma movimentação de 60 bilhões de reais, representando $1,6 \%$ do PIB e 18\% da matriz energética. Gerou 4,5 milhões de empregos diretos e indiretos, envolvendo 72 mil agricultores. A moagem foi em torno de 620 milhões de toneladas de cana, da qual foram produzidos 38 milhões de toneladas de açúcar e 27,5 bilhões de litros de etanol. Além disso, recolheu 15 bilhões em impostos e taxas. Diante do exposto, fica evidente a importância desse setor produtivo para a economia brasileira.

O Brasil, responsável por mais da metade do açúcar comercializado no mundo, deve alcançar taxa média de aumento da produção de 3,25\% até 2018/19 e colher 47,34 milhões de toneladas do produto, o que corresponde a um acréscimo de 14,6 milhões de toneladas em relação ao período 2007/2008. Para as exportações, o volume previsto para 2019 é de 32,6 milhões de toneladas.

O etanol, produzido no Brasil a partir da cana-de-açúcar, também conta com projeções positivas para os próximos anos, devido, principalmente, ao crescimento do consumo interno. A produção projetada para 2019 é de 58,8 bilhões de litros, mais que o dobro da registrada em 2008. 0 consumo interno está projetado em 50 bilhões de litros, e as exportações em 8,8 bilhões (MAPA, 2012). 


\section{GESTÃO AMBIENTAL: UM ESTUDO EM EMPRESAS DO SETOR SUCROALCOOLEIRO EM GOIÁS}

O Estado de Goiás é o quarto maior produtor de cana-de-açúcar do país, com 601,2 mil hectares de área estimada de cana colhida, o que corresponde a 7,4\% da área total estimada para o Brasil, que é de 8.091,5 mil hectares (CONAB, 2010). A área cultivada com a cana-de-açúcar em Goiás aumentou nos últimos anos, e a previsão é de que, conforme o aumento do consumo de etanol e a necessidade de aumento da produção para atender ao crescimento do mercado interno e suprir as exportações, se mantenha o processo de incorporação de novas áreas para a expansão da cultura canavieira em Goiás. De 2004 a 2010, o incremento da área ocupada com cana foi de aproximadamente 335\% (421,9 mil hectares).

Diante desse cenário, fica evidente que há muitas oportunidades que podem ser exploradas rumo ao desenvolvimento socioeconômico, embora existam impactos diretos e indiretos no meio ambiente, os quais demandam ações racionais por parte das empresas.

\section{Goiás: contexto histórico e características}

Em Goiás, o processo de ocupação do território iniciou-se, a partir dos anos de 1920, pela busca de metal precioso, especificamente, do ouro.

Foi a partir de 1910 que a economia goiana, lentamente, passou a integrar a economia nacional. 0 estado de Goiás deparou-se com gargalos, principalmente no que diz respeito à infraestrutura, que dificultavam o seu desenvolvimento.

Carrijo (2008) cita que a atuação do Estado foi decisiva para que houvesse a ocupação do cerrado. Na região Centro-Oeste, havia áreas extensas de cerrado. Na década de 1970, um conjunto de fatores contribuiu para fazer da região Centro-Oeste, onde se insere o estado de Goiás, a área mais promissora da fronteira agrícola. Os planos governamentais, a infraestrutura, as modificações da base técnica agropecuária, os modelos desenvolvidos pela revolução verde, que por meio da tecnologia resolveram problemas da fertilidade do solo, contribuíram para expansão da fronteira agrícola nesta região. A modernização do Estado de Goiás foi marcada pelos financiamentos rurais obtidos na década de 1970.

A economia goiana está fundamentada na agricultura, produção de grãos e pecuária. A crescente expansão da atividade canavieira para áreas produtoras de grãos e pecuária tem levantado debates no que diz respeito a um possível desequilíbrio na produção de alimentos.

Hoje, as atividades do setor sucroalcooleiro têm avançado em várias partes do país, principalmente no estado de São Paulo e na região Centro-Oeste. A atividade canavieira está expandindo dos polos produtores para regiões onde o cultivo era de importância secundária, como por exemplo, no estado de Goiás.

Segundo dados do IBGE (2007), as estatísticas gerais mostram que a área plantada, destinada à cana-de-açúcar, em Goiás, cresceu de 106.826 hectares, em 1990, para 200.048 hectares, em 2005, enquanto a área colhida foi de 97.950 hectares e 196.596 hectares, respectivamente. Complementarmente, analisando o desempenho sucroenergético em Goiás, a produção da canade-açúcar na safra de 2000/01 foi de 7.161.000 toneladas, saltando para 45.220.066 toneladas na safra de 2011/12, com previsão de evolução nas próximas safras (SIFAEG, 2013).

A difusão ou expansão das empresas sucroalcooleiras no estado de Goiás ocorre devido a algumas vantagens, como: preço baixo das terras para compra ou arrendamento em relação às outras regiões do país; fatores geográficos, como topografia plana, solo e clima favoráveis e disponibilidade de recursos hídricos; grandes extensões de terras agricultáveis e boa infraestrutura urbana (CARRIJO, 2008). 
A região Centro-Oeste é conhecida como área de grande potencial agrícola. Atualmente, o estado de Goiás apresenta grande potencial para expansão da atividade canavieira, devido às vantagens citadas. Assim, o setor atrai consideráveis investimentos. Este estado pode ser considerado como um dos maiores polos energéticos do país e é o $6^{0}$ colocado na produção nacional de açúcar e etanol. Atualmente, estão em funcionamento 34 empresas sucroalcooleiras.

\section{Práticas, impactos, oportunidades e desafios no setor sucroalcooleiro}

O Brasil, apontado como o principal país que dispõe de conhecimento, experiência e recursos naturais para atender à crescente demanda mundial por produtos derivados da cana-de-açúcar, é visto como um dos principais beneficiários das novas oportunidades que se abrem no mercado mundial. Por outro lado, surgem questionamentos sobre o uso dos recursos naturais na cultura e no processamento da cana-de-açúcar. Estes questionamentos socioambientais sobre a cadeia produtiva do etanol brasileiro já motivam alguns países importadores, especialmente da União Europeia, a exigir certificados que comprovem a sustentabilidade socioambiental da sua base produtiva (SANTO e ALMEIDA, 2007). Diante deste fato, uma instituição não governamental sediada em Genebra estipula um conjunto de normas ambientais, a ISO 14000, que visa estabelecer critérios e sistemas para a administração ambiental em uma organização (MONTEIRO e FERREIRA, 2009).

Dessa forma, considerando-se os padrões de produção atuais, independente do tipo de atividade agrícola, ao se fazer uso de recursos naturais e usar insumos agrícolas de natureza química, certamente algum tipo de impacto ambiental estará ocorrendo. Apesar disso, as discussões em torno do tema abordado mostram também impactos positivos relacionados a esse sistema produtivo.

No que tange aos impactos das atividades produtivas do setor sucroalcooleiro sobre o meio ambiente, são considerados os seguintes aspectos:

a) Os impactos na qualidade do ar e no clima, decorrentes da queima da palha da cana. Há ainda as emissões de gases que podem ser evitadas com o uso do etanol em substituição à gasolina. Inclui-se aqui a discussão sobre o balanço energético (de todo o ciclo de vida do produto), da utilização de energia fóssil na produção de etanol à energia renovável resultante;

b) Os impactos no suprimento e na qualidade da água;

c) A expansão da fronteira agrícola, que coloca em risco a biodiversidade;

d) 0 uso de defensivos agrícolas e a consequente contaminação do solo e dos recursos hídricos;

e) 0 desgaste dos solos agrícolas, causado pelas queimadas e pelo não reaproveitamento eficiente dos efluentes líquidos. (SANTO e ALMEIDA, 2007, p. 07).

Andrade (2009) complementa essa discussão ao afirmar que a produção da cana traz consigo:

a) Redução da biodiversidade, causada pelo desmatamento e pela implantação de monocultura;

b) Contaminação das aguas superficiais e subterrâneas e do solo, por meio da prática excessiva de adubação química, do uso de corretivos minerais e da aplicação de herbicidas e defensivos agrícolas;

c) Compactação do solo pelo tráfego de máquinas pesadas, durante o plantio, tratos culturais e colheita;

d) Assoreamento de corpos d água, devido a erosão do solo em áreas de reforma;

e) Emissão de fuligem e gases de efeito estufa na queima ao ar livre de palha, durante o período de colheita;

f) Danos à flora e a fauna, causados por incêndios descontrolados. (p. 129). 


\section{GESTÃO AMBIENTAL: UM ESTUDO EM EMPRESAS DO SETOR SUCROALCOOLEIRO EM GOIÁS}

Diante de tais aspectos, é inegável o potencial de impactos negativos para o meio ambiente e o ecossistema.

Entretanto, muitos estudos mostram que, a partir de um bom planejamento que contemple critérios para se buscar a eficiência no uso dos recursos naturais, pode-se ajudar a reduzir os impactos ao meio ambiente e, possivelmente, leva-lo a um melhor desempenho operacional e econômico. Corroborando esta afirmação, em uma pesquisa realizada por Andrade (2010) em uma usina no Estado de Goiás, concluiu-se que a empresa pesquisada persegue a sustentabilidade de suas operações ao diminuir o impacto ao meio ambiente e desenvolver ações que visam minimizar as disparidades sociais. 0 conjunto de todas essas ações socioambientais tem lhe possibilitado a obtenção de certificações e prêmios. Isso influencia, de forma distinta, aspectos como melhoria de sua imagem, condições de competitividade nos mercados existentes, criação de novas oportunidades de negócios, acesso a mercados internacionais e desempenho financeiro.

Nota-se, portanto, que há alguns avanços em relação a algumas práticas agrícolas aplicadas ao setor, que tendem à preservação do meio ambiente.

A utilização de fertilizantes na cultura de cana-de-açúcar no Brasil (aproximadamente 0,425 tonelada por hectare) é considerada baixa, fato que amplia o debate. Isto se deve principalmente à utilização de resíduos industriais oriundos da produção do etanol e do açúcar, como a vinhaça e a torta de filtro, usados como fertilizantes orgânicos. A vinhaça, aplicada na lavoura em substituição à adubação, tem potencial de trazer benefícios econômicos e melhorar a produtividade, pois é rica em matéria orgânica e em nutrientes minerais, mesmo não podendo ser aplicada à lavoura de forma indiscriminada por possuir potencial poluidor para o meio ambiente.

Além disso, a palha da cana deixada sobre o solo, após a colheita, principalmente nas áreas mecanizadas, contribuem para otimizar esse processo em termos de reciclagem de nutrientes e proteção do solo (UNICA, 2012).

Há quem defenda que a cultura canavieira demanda poucas aplicações de produtos químicos em comparação a outras culturas de produção extensiva, em razão de sua rusticidade e adaptação às condições edafoclimáticas em que é cultivada no Brasil. Dentre os agrotóxicos aplicados nos canaviais, os herbicidas é o tipo mais utilizado. Além disso, muitos produtores utilizam o controle biológico ${ }^{2}$ de pragas (ANDRADE, 2009; 2010). No tocante aos inseticidas usados na cana-de-açúcar, no Brasil, o volume pode ser considerado baixo, e o de fungicidas é praticamente nulo. As principais pragas da cana estão sendo combatidas através do controle biológico de pragas e da seleção de variedades resistentes em programas de melhoramento genético (UNICA, 2012).

No que diz respeito às perdas do solo, a cultura da cana no Brasil é reconhecida hoje por apresentar, relativamente, pequena perda de solo (cerca de 12,4 toneladas por hectare). Esta situação tem melhorado com o aumento da colheita sem a queima da palha de cana e com técnicas de preparo reduzido, levando a menores impactos (Ibidem).

Considerando-se a captação de água do meio ambiente, Piacent (2006) avalia que a eminente escassez de água e o comprometimento de sua qualidade em algumas regiões do mundo chamam a atenção para a importância do planejamento e da gestão deste precioso recurso. A cultura da cana-de-açúcar no Brasil, tradicionalmente, não utiliza irrigação, o que é de grande

\footnotetext{
2 Técnica de introduzir no ecossistema um inimigo natural (predador ou parasita) da espécie nociva. Esse método pode acarretar em evidentes vantagens em relação ao uso de agentes químicos, uma vez que não polui o ambiente.
} 
importância na redução de impactos ambientais (não só pelo menor uso da água, como também por evitar arrastes de nutrientes, resíduos agrotóxicos, perdas de solo etc.). Ainda assim, o processo de produção de açúcar e álcool utiliza um volume considerável de água. Contudo, vale destacar os esforços que este setor produtivo vem realizando para diminuir o consumo, procurando otimizar seus processos e reorientando seu planejamento para a reciclagem deste bem (Ibidem).

Nessa mesma linha, a UNICA (2012) considera que as necessidades hídricas da cana, na fase agrícola, são sanadas naturalmente pelo regime de chuvas das regiões produtoras e complementadas pela aplicação da vinhaça, um processo chamado fertirrigação. Assim, os níveis de captação de água para uso industrial têm sido reduzidos nos últimos anos de cerca de $5 \mathrm{~m}^{3}$ por tonelada de cana para cerca de $1 \mathrm{~m}^{3}$ por tonelada processada.

Vale destacar uma prática que vem sendo utilizada no setor em conformidade ao que defende Rahman et al (2009). Diz respeito a um processo chamado cogeração, que consiste na produção simultânea de energia térmica e elétrica a partir da biomassa (resíduo do processo produtivo), capaz de suprir as necessidades da usina e prover quantidade excedente para comercialização. Desta maneira, parte da energia utilizada no processamento da cana no Brasil é gerada dentro das próprias usinas, a partir da queima do bagaço da cana (UNICA, 2012). Comparando a queima do bagaço com outros combustíveis fósseis, ela pode ser mais limpa, uma vez que praticamente não libera óxidos de enxofre, relativamente comuns na queima de combustíveis fósseis (PIACENT, 2006).

Segundo algumas estimativas calculadas com base na análise de ciclo de vida do produto, o etanol, produzido de cana-de-açúcar, reduz as emissões de gases de efeito estufa (GEEs) em mais de $80 \%$ em substituição à gasolina (UNICA, 2012). Outro fato é como as plantas captam $\mathrm{CO}_{2}$ da atmosfera para crescer (fotossíntese), como se segue: $\mathrm{CO}_{2}$ formado durante a combustão é equilibrado pelo que é absorvido durante o crescimento anual das plantas utilizadas como matéria-prima (cana-de-açúcar), ao contrário da queima de combustíveis fósseis (KIKUCHI et al, 2009).

Por outro lado, segundo Andrade (2009, p. 130), "dados coletados diretamente com as empresas agrícolas e referentes à safra 2006-2007 apontam consumo médio de óleo diesel de 2,9 litros por tonelada de cana. Um fato que sinaliza mecanização crescente e necessidade de otimização da logística de transportes". Sabe-se que o consumo deste combustível representa novas emissões dos GEEs e maiores impactos no aquecimento global. Soma-se a isso a prática de queima da palha da cana-de-açúcar, que provoca emissões para a atmosfera de material particulado, como monóxido de carbono ( $\mathrm{CO}$ ) e dióxido de carbono $\left(\mathrm{CO}_{2}\right)$. Com as queimadas, há aumento da temperatura do solo, o que causa perda de nitrogênio e da camada bacteriana. A emissão de fuligem e fumaça traz problemas respiratórios para a população.

Desse modo, está previsto um calendário para redução gradual das queimadas, até 2014, nas áreas mecanizáveis, e até 2017, em áreas onde a colheita não é mecanizada (ANDRADE, 2009). Sabe-se que a colheita mecanizada da cana deixa na área colhida uma quantidade significativa de material orgânico, que favorece o solo, possibilitando reduzir o uso de agrotóxicos.

\section{Metodologia}

Esta pesquisa utiliza os fundamentos da abordagem qualitativa e exploratória e pode ser caracterizada como uma pesquisa de campo. A pesquisa de campo, segundo Marconi e Lakatos (2004), pode ser usada para comprovar hipóteses e/ou adicionar informações a uma situação problema, possibilitando uma associação com os dados coletados na pesquisa bibliográfica, o 


\section{GESTÃO AMBIENTAL: UM ESTUDO EM EMPRESAS DO SETOR SUCROALCOOLEIRO EM GOIÁS}

que pode gerar conclusões novas para os registros existentes e/ou novos problemas a serem resolvidos.

Um dos fatores que limitou a elaboração deste trabalho foi a dificuldade, por parte das usinas, de obter dados durante a pesquisa de campo. De um total de 36 usinas no Estado de Goiás, associadas ao Sindicato da Indústria de Fabricação de Açúcar e Etanol do Estado de Goiás (SIFAEG), 34 foram convidadas a participar da pesquisa. As outras duas não foram convidadas por dificuldade de fazer contato. Ao se fazer o convite, foi explicado o objetivo da pesquisa e informado que não seriam divulgados os nomes das empresas, visando resguardá-las. A maioria das usinas se recusou a participar da pesquisa e agradeceu o convite. Com isto, apenas quatro usinas concordaram em participar, as quais se tornaram objeto de estudo e são denominadas, neste estudo, de empresas A, B, C e D.

Para a coleta de dados, utilizou-se um questionário contendo 20 questões abertas, dividido em blocos, enfocando aspectos como: questões gerais sobre cada usina; motivações para a adoção de iniciativas ambientais; certificação ISO 14000; cuidados relacionados com a água e o solo; relacionamentos com fornecedores; gerenciamento de resíduos do sistema produtivo; respeito aos padrões de preservação ambiental como fator de decisão de compra; fortalecimento da imagem corporativa; oportunidades econômicas no gerenciamento das questões ambientais e desafios ou barreiras para a sustentabilidade no setor sucroalcooleiro.

Essa estratégia teve o intuito de entender questões específicas relacionadas às práticas ambientais utilizadas por cada empresa. 0 questionário foi enviado por e-mail para ser respondido pela pessoa ocupante do cargo de gestor ambiental. Vale destacar que este respondente foi selecionado por ser o colaborador que se relaciona diretamente com os assuntos pertinentes à gestão ambiental das empresas. Demorou cerca de 25 dias para que os questionários retornassem.

Além do uso do questionário para coleta de dados, foi feita visita in loco em uma usina estudada para coleta de mais evidências. Complementarmente, foram feitos vários contatos por telefone e $e$-mail com as empresas pesquisadas para maiores esclarecimentos das questões levantadas.

Posteriormente, os dados coletados foram transcritos e submetidos à análise qualitativa. Os principais resultados foram discutidos em seguida.

\section{Resultados e discussões}

Hoje, o setor sucroalcooleiro enfrenta muitos desafios, seja pela legislação aplicada ou pela exigência de agentes externos ao setor. Neste sentido, pode-se dizer que as usinas em Goiás, gradativamente, vêm buscando se adaptar ao adotar programas ambientais apropriados às demandas do ecossistema. Percebe-se, também, que elas têm procurado acompanhar a mudança de perfil do consumidor e melhorar sua imagem e competitividade frente à concorrência nacional e internacional.

Portanto, este trabalho busca identificar e analisar as práticas ambientais adotadas pelas empresas do setor sucroalcooleiro em Goiás. Em seguida, são destacadas as principais ações e outras considerações sobre cada usina pesquisada, denominadas aqui de A, B, C e D.

\section{Usina A}

A usina A foi fundada em fevereiro de 1987. Hoje, ela é uma cooperativa, fatura em média R\$ 100 milhões anuais e conta com aproximadamente 1.950 colaboradores. Produziu, na safra de 2009/2010, 1,4 milhões de toneladas de cana-de-açúcar. 0 único produto comercializado, 
atualmente, é o etanol, e esta organização ainda não exporta o produto. A partir da safra de 2012/13, a empresa espera elevar e diversificar sua produção, pois está em fase de expansão sua planta industrial para fabricação de açúcar. A média de produção de seu principal produto, o etanol, é de 109 mil litros/ano.

Quanto à existência de programas relacionados ao meio ambiente, a empresa informa que ainda não existe um Sistema de Gerenciamento Ambiental (SGA), mas que foi criada uma equipe responsável por fiscalizar, desenvolver e implementar ações e soluções para as questões de natureza ambiental, no que diz respeito às motivações para seu engajamento com as seguintes questões:

a) Motivações para a adoção de iniciativas ambientais: esta organização considera que as principais motivações para as iniciativas socioambientais se baseiam na crença de que, atualmente, não se concebe um empreendimento sem o cumprimento das exigências socioambientais. Alinhado ao que defendem Alperstedt et al (2010), tanto os públicos interno como os externo, como funcionários, cooperados, governo, sindicato, comunidade, instituições financeiras, entre outros, exigem práticas que atendam às suas expectativas de forma equilibrada. Foi salientado ainda que, para as atividades de preservação ao meio ambiente progredirem, uma cultura da responsabilidade socioambiental tem que estar impregnada na estrutura da organização.

Questionou-se sobre o que é mais significante para esta organização, se as multas aplicadas por órgãos de fiscalização ambiental, ou a busca de maior eficiência e competitividade relacionada à proposta de sustentabilidade. Portanto, ressaltou-se que as multas têm um significado importante, pois, além de elevarem os custos, a imagem da empresa é difundida na comunidade como agressora do meio ambiente. Entretanto, a busca da sustentabilidade, observando-se os padrões da legislação ambiental, evita estes impactos negativos, deixando a empresa em melhores condições.

b) Certificação ISO 14000: a certificação ISO 14000 exige a adequação de técnicas, desde o início da plantação até o produto acabado, em prol do meio ambiente (SANTO e ALMEIDA, 2007; MONTEIRO e FERREIRA, 2009). Portanto, esta certificação ainda não existe nesta organização, mas está-se ciente da importância da obtenção desta certificação.

c) Cuidados relacionados à água e ao solo: para que a atividade econômica aqui enfocada tenha longevidade, os cuidados com o solo e a busca pela manutenção do equilíbrio do meio ambiente são fundamentais. Neste sentido, sobre o gerenciamento de riscos para antecipar ameaças à atividade operacional e processos operacionais existentes para evitar acidentes com impacto ambiental, é realizada uma avaliação prévia dos impactos potenciais. Posteriormente, são tomadas as providências cabíveis para cada situação identificada. Tais ações abarcam desde a escolha das áreas para plantação das lavouras, o preparo do terreno, plantio, os tratos culturais, a colheita e o transporte da matéria-prima, até a área de processamento industrial.

Em relação às preocupações com as matas ciliares, que têm como função a preservação de recursos hídricos e a biodiversidade para a plantação das lavouras de cana, a organização respeita as áreas de preservação permanente (APPs), onde estão inseridas estas matas ciliares. Isto não é somente para atender a legislação ambiental, segundo a empresa, mas para compreender a importância desta ação para sustentabilidade da atividade produtiva e preservação dos recursos naturais.

As ações adotadas para reduzir a captação de água do meio ambiente acontecem por meio da construção de reservatórios para armazenamento de águas pluviais. Esta prática vai de encontro aos argumentos de Piacent (2006) e ÚNICA (2012). Em conformidade ao que ressaltam Andrade (2009) e ÚNICA (2012) quanto às iniciativas para se evitar contaminar os 


\section{GESTÃO AMBIENTAL: UM ESTUDO EM EMPRESAS DO SETOR SUCROALCOOLEIRO EM GOIÁS}

recursos hídricos ao fazer uso de produtos químicos (inseticidas, herbicidas) para tratar a cultura canavieira, o controle biológico de algumas pragas é adotado para diminuir a aplicação destes produtos. Além disso, a empresa informa que, na aplicação dos agroquímicos, são seguidas as recomendações do receituário agronômico.

d) Relacionamentos com fornecedores: no que diz respeito aos relacionamentos colaborativos com fornecedores para desenvolver processos inovadores ou novas soluções para desafios ambientais (ZHU e COTE, 2004; WALTON, et al, 1998; SANCHES, 2000; KUSHWAHA, 2010), a organização afirma que desenvolve projetos de recuperação de áreas degradadas nas terras destinadas ao plantio, principalmente nas áreas de preservação permanente. Nestas áreas é feito o reflorestamento com espécies de plantas nativas regionais. São, também, construídos terraços para conservação dos solos nas áreas adjacentes às lavouras de cana.

Sobre as ações de orientações aos fornecedores para a preservação ambiental, prevenção da poluição e outras questões de interesse mútuo, ainda não existem programas estruturados dessa natureza.

e) Gerenciamento de resíduos do sistema produtivo: sabe-se que toda atividade de processamento industrial, particularmente na produção do açúcar e etanol, gera subprodutos ou resíduos, como a vinhaça, o bagaço e a torta de filtro. Todavia, a reciclagem, o reuso e o destino correto destes reduzem os impactos ambientais. Portanto, é importante estabelecer controles e metas para reduzir ou reutilizar esses resíduos do processo produtivo.

Diante de tais considerações, de acordo com Abreu (2001), pode-se dizer que há, nesta empresa, uma conduta ambiental do tipo intermediária, considerando-se a avaliação quantitativa de sua performance ambiental. Para a organização A, existem esforços contínuos de medição de desempenho, e a adoção de novos processo e técnicas é sempre buscada, objetivando-se gerenciar os resíduos. Um exemplo pode ser o reuso do bagaço da cana para fabricação de energia elétrica. De acordo com os argumentos da UNICA (2012), a energia elétrica consumida no período da safra é produzida a partir do bagaço da cana. Existe, inclusive, um projeto em andamento de cogeração para comercialização do excedente produzido. 0 que motiva esta estratégia é, principalmente, a possibilidade de melhor retorno econômico. Nota-se, portanto, avanços quanto ao destino ambientalmente correto dos resíduos, gerados no processo industrial.

As iniciativas realizadas para a redução de emissões atmosféricas do sistema de transporte resumem-se em transportar o máximo de cana por carga, da área de cultura até a planta industrial, e manter sempre regulados os motores dos veículos e máquinas.

Sabe-se que a prática da queima da palha da cana provoca emissões para a atmosfera, contudo, a prática de colheita mecanizada não requer a queima da palha. A colheita mecanizada, nesta empresa, decorre da necessidade de adequações à legislação trabalhista e ambiental. Do total de cana colhida, o percentual feito por colheitadeira mecânica está pouco acima de 50\%. Esta organização considera que, com a exigência de redução da queima, somada à escassez da mão de obra para o corte manual, torna-se imperioso a utilização da colheita mecanizada.

f) Respeito aos padrões de preservação ambiental como fator de decisão de compra: quando questionado se o mercado aceitaria pagar um preço premium (superior) por um produto produzido dentro dos padrões de preservação ambiental, foi salientado que sim, principalmente o mercado internacional, que em muitos casos exige certificações ambientais. Por outro lado, em consonância às afirmações de Machado e Pimenta (2004) e Segatto-Mendes e Lemos (2007), acredita-se, também, que um produto produzido dentro dos padrões de preservação ambiental é fator que pode influenciar na decisão de compra dos mercados nacionais e internacionais. 
g) Fortalecimento da imagem corporativa: à luz do que salientam Nascimento (2007), Claro et al (2008) e Segatto-Mendes e Lemos (2007), em se tratando de um possível fortalecimento da imagem corporativa a partir da adoção de práticas ligadas à sustentabilidade, a empresa argumenta que os esforços empreendidos buscam esta condição. Considera-se, ainda, que se não há preocupações rumo a um padrão de produções sustentáveis, a empresa pode não ser competitiva no atual mercado globalizado.

h) Oportunidades econômicas no gerenciamento das questões ambientais: alinhada ao que ressaltam Rahman et al (2009) e Sanches (2000) quanto às possíveis oportunidades econômicas ligadas às iniciativas para eliminação ou diminuição de resíduos gerados no processo produtivo, esta organização acredita que, aumentando a eficiência produtiva no setor agrícola e industrial, certamente diminuirá a geração de resíduos, resultando em potenciais ganhos ambientais e econômicos. Como exemplo, há o caso da vinhaça usada na fertirrigação da lavoura, que permite um destino ambientalmente correto para ela, diminuindo o uso de fertilizantes químicos, aumentando a produtividade e longevidade dos canaviais e melhorando a rentabilidade.

Essa empresa considera que práticas relacionadas à preservação ambiental, como a racionalização no uso de produtos químicos na lavoura, podem influenciar na redução dos custos, possibilitando maior rentabilidade.

Quando questionada se tem sido possível alcançar melhores resultados econômicos ao contribuir com as questões ambientais, foi salientado que a preocupação com as questões ambientais e sociais garantirá a sustentabilidade de suas operações e produção. Inclusive, a empresa diz que percebe um aumento da produtividade agrícola decorrente de suas preocupações e ações ambientais já iniciadas.

i) Desafios ou barreiras para a sustentabilidade no setor: em se tratando de desafios ou barreiras para a sustentabilidade no setor, foram pontuados: indefinição quanto ao novo código florestal, que traz preocupações e incertezas quanto ao futuro da atividade; entraves burocráticos para a liberação de licenças ambientais; outorgas de uso de água pelos órgãos competentes e, por fim, os feitos da sociedade em compreender a importância socioambiental que o setor sucroalcooleiro representa para o Brasil.

\section{Usina B}

A usina B foi fundada em julho de 1980, sendo uma das empresas pioneiras do setor. Preferiu não informar seu faturamento anual e conta atualmente com aproximadamente 1000 colaboradores. Produziu, na safra de 2009/2010, 1 milhão de tonelada de cana-de-açúcar. A capacidade de produção de sua planta industrial é de 1.600 .000 toneladas de cana-de-açúcar. A média de produção de seus principais produtos, o etanol, é de $103.000 \mathrm{~m}^{3}$ /ano; quanto ao açúcar, a empresa não fabrica.

Quanto a seu engajamento com as causas ambientais, pode-se citar:

a) Motivações para a adoção de iniciativas ambientais: para esta empresa, é mais significante a busca pela sustentabilidade, com o intuito de obter eficiência e competitividade em suas operações. Uma das principais políticas da empresa, segundo informado, é o atendimento à legislação ambiental vigente e a implantação de ações sustentáveis que possibilitem a sustentação de sua atividade econômica.

b) Certificação ISO 14000: de acordo com o que destaca Santo e Almeida (2007), esta empresa ainda não possui esta certificação, o que pode ser considerado um fator impeditivo para a venda 


\section{GESTÃO AMBIENTAL: UM ESTUDO EM EMPRESAS DO SETOR SUCROALCOOLEIRO EM GOIÁS}

de seus produtos para países exigentes, como por exemplo, os europeus.

c) Cuidados relacionados à água e ao solo: quando questionada sobre as ações de gerenciamento de riscos para antecipar ameaças à atividade operacional, esta empresa afirma que tem uma equipe qualificada para estas questões, que avalia os processos relacionados aos fatores ambientais, planeja e busca executar as ações cabíveis.

Para a expansão da lavoura canavieira, as matas ciliares são respeitadas e, quando estiverem degradadas, far-se-á o replantio com espécies nativas (informação da empresa).

Outro fato é que ainda não existem programas para reduzir a captação de água, mas há uma planta industrial em fase de projeto contemplando este processo. Quanto às iniciativas existentes para evitar contaminar os recursos hídricos ao utilizar produtos químicos para tratar a cultura canavieira, a empresa procura utilizar agroquímicos com menores riscos ao meio ambiente. Trabalha-se, também, com a construção de proteções (curvas de nível de base embutida) às proximidades das APP's, na tentativa de prevenir possíveis acidentes.

d) Relacionamentos com fornecedores: em se tratando dos relacionamentos colaborativos com fornecedores procurando desenvolver novas soluções para desafios ambientais (ZHU e COTE, 2004; WALTON, et al, 1998; SANCHES, 2000; KUSHWAHA, 2010), a empresa informa que esta prática ainda não está presente em suas operações. Portanto, há uma lacuna a ser preenchida para que a empresa avance em direção aos padrões de respeito ambiental.

e) Gerenciamento de resíduos do sistema produtivo: a empresa explica que, mesmo estando em fase inicial, há um processo ainda pouco estruturado para estabelecer metas visando reduzir poluição e resíduos no processo produtivo. Portanto, de encontro ao que Abreu (2001) defende, esse perfil seria de uma empresa de conduta ambiental intermediária, por estar iniciando o processo de avaliação de desempenho ambiental.

Sobre a colheita mecanizada da cana-de-açúcar, hoje, em torno de $90 \%$ da área plantada é colhida usando o sistema mecanizado. Trata-se de um ponto positivo, uma vez que essa técnica possibilita deixar na área colhida uma quantidade significativa de material orgânico que favorece o solo, permitindo reduzir o uso de agrotóxicos (UNICA, 2012).

Argumentou-se, também, que as iniciativas para geração de energia a partir da biomassa (UNICA, 2012) são motivadas pelo baixo investimento necessário e menor impacto ambiental em relação às hidrelétricas. Atualmente, a empresa produz $100 \%$ da energia elétrica consumida internamente e existe um projeto em andamento para comercialização do excedente, o que possibilitará incremento em sua receita.

Há, ainda, investimentos em sistemas de lavadores de gases para evitar que sejam lançadas na atmosfera partículas poluidoras resultantes da queima do bagaço durante o processamento industrial.

f) Respeito aos padrões de preservação ambiental como fator de decisão de compra: esta empresa, ao ser questionada sobre a possibilidade do mercado pagar um preço premium por um produto produzido dentro dos padrões de preservação ambiental, acredita que ainda não há possibilidade, e que os produtos que contemplam a proposta de preservação ambiental não representam um fator que poderia influenciar na decisão de compra de clientes nacionais. Mas, mesmo assim, acredita que ações de responsabilidade socioambiental já são questionadas por clientes internacionais.

g) Fortalecimento da imagem corporativa: esta empresa acredita no fortalecimento da imagem 
corporativa a partir da adoção de práticas ligadas à sustentabilidade (NASCIMENTO, 2007; CLARO et al, 2008, SEGATTO-MENDES e LEMOS, 2007).

h) Oportunidades econômicas no gerenciamento das questões ambientais: em se tratando das possíveis oportunidades econômicas, a partir dos programas para eliminação ou diminuição de resíduos gerados no processo produtivo (RAHMAN et al, 2009; SANCHES, 2000), esta empresa procura reaproveitar alguns resíduos gerados no processo industrial, como a torta de filtro e a vinhaça, em substituição ao adubo químico. A primeira, rica em matéria orgânica e fósforo, é usada na adubação durante o plantio. Atualmente, $30 \%$ da área plantada recebe fertirrigação com a vinhaça, o que representa, para esta empresa, possibilidade de diminuição de custos e maior rentabilidade.

i) Desafios ou barreiras para a sustentabilidade no setor: sobre este aspecto, a empresa preferiu não se manifestar.

\section{Usina C}

A usina C preferiu não informar seu faturamento anual, e conta, atualmente, com aproximadamente 940 colaboradores. Produziu, na safra de 2009/2010, 850 mil toneladas de cana-de-açúcar. Hoje, comercializa seus produtos somente no mercado interno. A média de produção de seus principais produtos, o etanol, é $75.000 \mathrm{~m}^{3}$ /ano; quanto ao açúcar, a empresa

não o fabrica.

Esta empresa não possui um Sistema de Gestão Ambiental, mas tem um gestor ambiental responsável pela área ambiental, o qual conta com o auxílio de uma equipe e uma consultora externa. Esta última orienta-o em suas atividades e ajuda a planejar ações para um melhor desempenho ambiental.

a) Motivações para a adoção de iniciativas ambientais: foi questionado sobre o que é mais significante para esta empresa, se as multas aplicadas por órgãos de fiscalização ambiental ou a busca de maior eficiência e competitividade, relacionada à proposta de sustentabilidade. Deste modo, foi informado que é mais importante as preocupações na busca por sustentabilidade.

b) Certificação ISO 14000: esta empresa não possui tal certificação, e isto pode ser considerado um ponto fraco diante do aumento da demanda por produtos ambientalmente corretos (SANTO e ALMEIDA, 2007).

c) Cuidados relacionados à água e ao solo: sobre as ações de gerenciamento de risco, visando antecipar ameaças à atividade operacional, a empresa enfatiza que suas ações relacionadas ao meio ambiente são previamente planejadas, implementadas e, posteriormente, acompanhadas por uma equipe qualificada. Sobre os cuidados tomados para expansão da lavoura canavieira, podem ser citadas as ações de proteção às matas ciliares, que têm como função a preservação de recursos hídricos e a biodiversidade. Neste sentido, a empresa salienta que está atenta à questão e procura preservar as áreas de proteção permanente.

Quanto às ações utilizadas para reduzir a captação de água, a empresa afirma que utiliza este recurso somente para atender a indústria, uma vez que a cultura é irrigada somente com a vinhaça disponível (PIACENT, 2006; UNICA, 2012).

As iniciativas presentes para evitar contaminar os recursos hídricos ao utilizar produtos químicos para tratar o solo e a cultura, resumem-se no distanciamento dos cursos de água e nascentes, conforme previsto nas normas ambientais. Em áreas próximas à cultura de cana-deaçúcar, empregam-se as inseticidas e herbicidas de forma limitada, restringindo-se apenas ao tratamento direcionado aos toletes. Adota-se, também, o controle biológico de pragas para 


\section{GESTÃO AMBIENTAL: UM ESTUDO EM EMPRESAS DO SETOR SUCROALCOOLEIRO EM GOIÁS}

combater principalmente pragas, como a broca da cana e a cigarrinha das raízes (ANDRADE, 2009; UNICA, 2012).

d) Relacionamentos com fornecedores: os relacionamentos colaborativos com fornecedores, com o objetivo de desenvolver novas soluções para desafios ambientais (ZHU e COTE, 2004; WALTON, et al, 1998; SANCHES, 2000; KUSHWAHA, 2010), acontecem de forma que a empresa fornece mudas de plantas nativas para reflorestamento nas propriedades de seus fornecedores. Ainda não estão presentes, nesta empresa, iniciativas de orientações aos fornecedores, no sentido de incentivar a busca pela preservação ambiental, prevenção da poluição e outras questões de interesse mútuo. Portanto, há muito que avançar no que se refere aos relacionamentos na cadeia produtiva.

e) Gerenciamento de resíduos do sistema produtivo: em relação ao estabelecimento de metas para reduzir a poluição e os resíduos do processo produtivo, a empresa informa que estabelece metas e as implementa na busca por melhor desempenho. Quanto às ações para a redução de emissões atmosféricas do sistema de transporte utilizado, a empresa busca, gradativamente, renovar sua frota com a aquisição de veículos modernos, os quais são projetados, visando reduzir impactos no meio ambiente. Esta empresa também investe em geração de energia elétrica a partir da biomassa (UNICA, 2012), e o que a motiva a fazer isso é a busca por melhores ganhos econômicos e ambientais. Do total de energia consumido, $60 \%$, em média, é produzida pela empresa.

f) Respeito aos padrões de preservação ambiental como fator de decisão de compra: para esta empresa, ao ser questionada se o mercado aceitaria pagar um preço premium por um produto produzido dentro dos padrões de preservação ambiental, há possibilidade e acredita já haver uma grande demanda por produtos ambientalmente corretos. No que tange a produtos, estes, quanto à possibilidade de influenciar na decisão de compra dos clientes nacionais e internacionais (MACHADO e PIMENTA, 2004; SEGATTO-MENDES e LEMOS, 2007), a empresa argumenta que principalmente os clientes internacionais preferem esse tipo de produto, pois alguns países compram somente de usinas com certificação ambiental. A empresa considera que as práticas de responsabilidade socioambiental já são questionadas por clientes nacionais e internacionais, mas com maior ênfase nesses últimos.

g) Fortalecimento da imagem corporativa: no que se refere à possibilidade de fortalecimento da imagem corporativa, a partir da adoção de práticas ligadas à sustentabilidade, a empresa acredita que esse compromisso com o meio ambiente possibilita ganhos de imagem e melhor competitividade (NASCIMENTO, 2007; CLARO et al, 2008; SEGATTO-MENDES e LEMOS, 2007).

h) Oportunidades econômicas no gerenciamento das questões ambientais: no que diz respeito às possíveis oportunidades econômicas ligadas aos programas para eliminação ou diminuição de resíduos do processo produtivo (RAHMAN et al, 2009; SANCHES, 2000), a empresa considera que o uso da vinhaça para fertirrigação da lavoura representa uma oportunidade de diminuição de custos e maior rentabilidade. Este resíduo, além de ter propriedade fertilizante, possui matéria orgânica que atua como condicionador do solo, melhorando suas características químicas, físicas e biológicas.

A empresa considera que as práticas de preservação ambiental, decorrentes da racionalização no uso de produtos químicos, podem influenciar na redução dos custos, possibilitando maior rentabilidade. Por exemplo, ela faz uso do controle biológico da broca da cana, que dispensa o uso de produtos químicos, e trata-se de um método de controle sustentável (ANDRADE, 2009; ÚNICA, 2012).

A empresa, quando questionada se seus resultados econômicos têm melhorado ao contribuir 
com as questões ambientais, afirma que sim. Para ela, quando uma empresa se dedica a estes aspectos, os resultados serão positivos, pois há o reconhecimento pela sociedade. Assim, esse fato contribui para gerar um tipo de vantagem competitiva.

i) Desafios ou barreiras para a Sustentabilidade no setor: esta empresa salienta que, atualmente, o grande desafio é atender à demanda por álcool e açúcar, sem uma política de incentivos do governo.

\section{Usina D}

A usina D foi fundada em 1986. Hoje, fatura uma média de R 50 milhões por ano e conta com aproximadamente 700 colaboradores. Produziu, na safra de 2009/2010, 470 mil toneladas de cana-de-açúcar. Atualmente, atua somente no mercado interno. A média de produção do etanol é 40 mil litros/ano. Quanto ao açúcar, a empresa não fabrica.

A empresa D relaciona as seguintes ações ambientais:

a) Motivações para a adoção de iniciativas ambientais: sua postura de responsabilidade socioambiental é motivada, principalmente, pelos seus valores organizacionais e também pelas exigências legais. A empresa pontua que, como as exigências por responsabilidade socioambiental são uma realidade mundial, é um requisito a organização se preparar para responder a essa demanda (WALTON, et al, 1998).

Ao ser indagada, esta empresa informa que é mais significante buscar maior eficiência e competitividade relacionada à proposta de sustentabilidade do que receber aplicações de multas pelos órgãos de fiscalização ambiental. Se ocorrer esta penalidade, a empresa teria seu passivo elevado.

b) Certificação ISO 14000: a empresa ainda não possui esta certificação e considera que é um ponto fraco a ser superado diante das exigências crescentes por produtos ambientalmente corretos, principalmente tratando-se das exigências dos países europeus (SANTO e ALMEIDA, 2007).

c) Cuidados relacionados à água e ao solo: as ações de gerenciamento de riscos e os processos operacionais para antecipar as ameaças à atividade operacional e os acidentes com impacto ambiental estão relacionadas às manutenções periódicas feitas pela empresa, conforme o que é diagnosticado em cada área. Há também programas específicos de treinamento aos funcionários. A empresa ainda afirma que procura respeitar e preservar as matas ciliares e as áreas de preservação permanente (APPs) ao expandir a lavoura canavieira.

As ações com o intuito de reduzir o uso e a captação de água acontecem para fazer o reuso das águas do processamento industrial.

Quanto às iniciativas para se evitar a contaminação dos recursos hídricos com o uso de produtos químicos para tratar o solo e a cultura canavieira, estão presentes: proteção das APPs e curvas de níveis e distanciamento mínimo de $200 \mathrm{~m}$ dos recursos hídricos ao aplicar os agroquímicos.

d) Relacionamentos com fornecedores: as ações colaborativas com fornecedores (ZHU e COTE, 2004; WALTON, et al, 1998; SANCHES, 2000; KUSHWAHA, 2010) sobre a preservação ambiental, prevenção da poluição e outras questões de interesse mútuo resumem-se em esclarecê-los sobre a importância da preservação das APPs e da reserva legal. A empresa exige, também, que seus fornecedores de cana-de-açúcar possuam essas áreas de preservação em suas propriedades.

e) Gerenciamento de resíduos do sistema produtivo: o estabelecimento de metas para reduzir a poluição e os resíduos no processo produtivo é visto como uma importante atitude para um 


\section{GESTÃO AMBIENTAL: UM ESTUDO EM EMPRESAS DO SETOR SUCROALCOOLEIRO EM GOIÁS}

melhor desempenho ambiental. Neste sentido, a empresa afirma que fixa metas ao gerenciar as questões ambientais, mas tal processo ocorre em estágio inicial e falta um gerenciamento mais efetivo do processo. De acordo com Abreu (2001), portanto, a empresa tem uma postura intermediária ao tratar de tais aspectos.

Com relação à alternativa da colheita mecanizada que ajuda a diminuir os impactos ambientais (UNICA, 2012), estima-se que, do total da colheita atual, em torno de $50 \%$ é feito por meio deste recurso, projetando-se um percentual de $75 \%$ para a próxima safra.

Ao questionar se há investimentos para a geração de energia a partir da biomassa, a empresa afirma que sim, e o que a motiva a fazer isto é a busca pela autossuficiência energética.

f) Respeito aos padrões de preservação ambiental como fator de decisão de compra: a empresa acredita que o mercado não aceita pagar um preço premium por um produto produzido dentro dos padrões de preservação ambiental (ANDRADE, 2010). Para esta empresa, um produto produzido dentro desses critérios é um fator que poderia influenciar na decisão de compra dos clientes nacionais e internacionais (MACHADO e PIMENTA, 2004; SEGATTO-MENDES e LEMOS, 2007). A empresa ainda cita exemplos de clientes exigentes, como a Petrobrás e Shell. As ações de responsabilidade socioambiental, segundo a empresa, já são questionadas por clientes nacionais.

g) Fortalecimento da imagem corporativa: a empresa acredita que há fortalecimento da imagem corporativa e melhor competitividade com adoção de práticas ligadas à sustentabilidade (NASCIMENTO, 2007; CLARO et al, 2008; SEGATTO-MENDES e LEMOS, 2007).

h) Oportunidades econômicas no gerenciamento das questões ambientais: ao questionar se a empresa acredita haver oportunidades econômicas ao eliminar ou diminuir os resíduos gerados no processo produtivo (RAHMAN et al, 2009; SANCHES, 2000), foi apontado que o uso da vinhaça para fertirrigação da lavoura representa possibilidade de diminuição de custos e maior rentabilidade. A alternativa proporciona ainda maior longevidade ao canavial e maior produtividade da cana-de-açúcar, embora falte à empresa desenvolver um projeto para gerenciar melhor questões de natureza ambiental.

No que tange à possibilidade de melhoria em seus resultados econômicos, ao contribuir com as questões ambientais, salientou-se que, no momento, a empresa não tem este objetivo. Assim, não há como mensurar e afirmar se houve ganhos ou perdas.

i) Desafios ou barreiras para a sustentabilidade no setor: neste sentido, são citados os altos custos dos equipamentos e maquinários necessários para o cultivo, a colheita, o processamento da cana e a falta de incentivo fiscal do governo.

Diante do exposto, em consonância à tipologia de Barbieri (2004), as discussões dos resultados mostram que as empresas analisadas, de modo geral, apresentam posturas reativa e proativa, pois as questões ambientais ainda não são tratadas de maneira estratégica.

Por fim, as evidências destacadas em cada caso permitem inferir que estas empresas estão mais comprometidas com os aspectos de preservação ambiental, embora tais esforços tenham muito que avançar para uma condição de sustentabilidade. 


\section{Considerações finais}

O objetivo deste estudo foi identificar e analisar as práticas ambientais adotadas pelas empresas do setor sucroalcooleiro em Goiás. Buscou-se, também, procurar respostas para questões relacionadas aos fatores que possam contribuir para a criação de vantagens competitivas dentro destas organizações. Para tanto, diante das considerações feitas anteriormente, notaram-se, nas empresas estudadas, muitas preocupações relacionadas à sustentação da atividade sucroalcooleira. Portanto, estas empresas, de forma unânime, já planejam e desenvolvem técnicas direcionadas à busca pela sustentabilidade de suas operações.

Como mostrado por Barbieri (2004), a abordagem ambiental nas empresas pode ser de três tipos. No primeiro tipo, a empresa tem uma postura reativa ao tratar as questões ambientais. No segundo, há um comportamento preventivo e, por fim, os fatores ambientais são tratados como uma questão estratégica. Desta maneira, percebe-se que as questões ambientais nas usinas aqui abordadas encontram-se no primeiro e segundo estágios, pois as ações são empreendidas como resposta às pressões dos órgãos regulamentadores e das comunidades (ALPERSTEDT et al, 2010). No entanto, são notórios os esforços iniciados para melhorar o desempenho ambiental. Por exemplo, ficou evidente o uso de técnicas mais racionais nas lavouras, bem como o reuso de resíduos do processo produtivo.

Complementarmente, diante da proposição de Abreu (2001), de modo geral a conduta ambiental das empresas estudadas se situa no nível intermediário, uma vez que elas estão iniciando o processo de medição do desempenho ambiental.

Na cultura e no processamento da cana-de-açúcar, certamente ainda são presentes impactos negativos para o meio ambiente. Apesar disso, ficou claro que a adoção das ações mencionadas, como: as técnicas que buscam a conservação do solo e da vegetação; a troca da queimada por colheitadeiras mecânicas; a racionalização no uso de produtos químicos; o reaproveitamento de resíduos do processo produtivo, como a geração de energia através de fonte renovável (o bagaço da cana); o reuso da vinhaça, dentre outras, apontam um novo rumo. Tais iniciativas apontam potencias benefícios para as empresas do setor e para o meio ambiente.

Dentre os esforços direcionados para aproveitar as oportunidades relacionadas ao meio ambiente, nota-se a busca por ganhos de imagem corporativa, bem como econômicos. Estes últimos seriam decorrentes do uso mais eficiente de insumos produtivos e reutilização de subprodutos do processamento industrial (RAHMAN et al, 2009; SANCHES, 2000).

Este estudo também procurou saber se na visão das usinas pesquisadas uma postura ambientalmente responsável poderia resultar em reações de decisões de compra por parte dos mercados nacionais e internacionais. Concluiu-se que o mercado interno já começou a direcionar suas escolhas para os produtos de tal natureza. Contudo, principalmente para o mercado internacional, o respeito aos padrões ambientais é fator decisivo para escolha do fornecedor.

Considerando o estágio atual da adoção de técnicas ambientalmente corretas pouco avançado, cabe ainda a esse setor fazer maiores investimentos no intuito de adequar seus processos em favor da preservação do meio ambiente, das próprias empresas do setor, governos e, principalmente, que traga bem-estar para as gerações atuais e futuras. Como foi destacado, talvez maiores investimentos no setor pudessem ser feitos, desde que as empresas fossem beneficiadas por incentivos governamentais.

Embora os dados da pesquisa não representem a totalidade das empresas sucroalcooleiras goianas, não sendo, portanto, possível, a generalização dos resultados, o estudo permite aos 
gestores e pesquisadores uma noção mais ampla do estágio atual de uma parcela das empresas em relação ao estabelecimento de estratégias ambientais.

Propõe-se que os estudos futuros desenvolvam uma nova perspectiva, que diagnostiquem a evolução da gestão ambiental no setor abordado em âmbito nacional e expliquem como essa mudança cria condições para a evolução da competitividade das empresas.

\section{Referências}

ABREU, M. C. S. Modelo de avaliação da estratégia ambiental: uma ferramenta para a tomada de decisão. 2001. 218 p. Tese de Doutorado em Engenharia de Produção, Programa de Pós-Graduação em Engenharia de Produção da Universidade Federal de Santa Catarina, Florianópolis, SC, 2001.

ALPERSTEDT, G. D; QUINTELLA, R. H; SOUZA, L. R. Estratégias de gestão ambiental e seus fatores determinantes: uma análise institucional. Revista de Administração de Empresas (RAE), v. 50 n. 2, p. 170-186, 2010.

ANDRADE, M. C. F. Green supply chain management e sustentabilidade na agroindústria canavieira: o caso Jalles Machado S/A. 2010. 135 p. Dissertação de Mestrado apresentada ao Centro de Ciências Econômicas da Universidade do Vale do Rio dos Sinos (UNISINOS), São Leopoldo, RS, 2010.

ANDRADE, J. M. F. Construção de um índice de sustentabilidade ambiental para a agroindústria paulista da cana-de-açúcar (ISAAC). 2009. 260 p. Dissertação de Mestrado. Escola de Economia de São Paulo da Fundação Getúlio Vargas, São Paulo, SP, 2009.

BARBIERI, J. C. Gestão ambiental empresarial. São Paulo: Saraiva, 2004.

CARRIJO, E. L. O. A expansão da fronteira agrícola no estado de Goiás: setor sucroalcooleiro. 2008. 101 p. Dissertação de mestrado apresentada ao programa de pósgraduação em Agronegócios da Universidade Federal de Goiás, Goiânia, GO, 2008.

ClARO, P. B. O.; CLARO, D. P.; AMÂNCIO, R. Entendendo o conceito de sustentabilidade nas organizações. Revista de Administração, v. 43, n. 4, p. 289-300, 2008.

COMPANHIA NACIONAL DE ABASTECIMENTO (CONAB). Disponível em: http://www.conab.gov.br/conabweb/download/safra/3 levantamento0708 nov2007.pdf Acesso em 25.01. 2012.

COUTINHO, R. B. G.; MACEDO-SOARES, T. D. A. Gestão estratégica com responsabilidade social: arcabouço analítico para auxiliar sua implementação em empresas no Brasil. Revista de Administração Contemporânea, v. 6, n. 3, p. 75-96, 2002.

DONAIRE, D. Considerações sobre a influência da variável ambiental na empresa. Revista de Administração de Empresas (RAE), v. 34, n. 2, p. 68-77, 1994.

INSTITUTO BRASILEIRO DE GEOGRAFIA E ESTATÍSTICA (IBGE). Disponível em: www.ibge.gov.br. Acesso em 12.09. 2013.

KIKUCHI, R; GERARDO, R.; SANTOS, S. M. Energy lifecycle assessment and environmental 
impacts of ethanol biofuel. International Journal of Energy Research, v. 33, n. 2 p. 186-193, 2009.

KUSHWAHA, G. S. Sustainable development through strategic green supply chain management. International Journal of Engineering and Management Sciences, v. 01, n. 1 p. 07-11, 2010.

LAYRARGUES, P. P. Sistemas de gerenciamento ambiental, tecnologia limpa e consumidor verde: a delicada relação empresa-meio ambiente no ecocapitalismo. Revista de Administração de Empresas (RAE), vol. 40, n. 2, p. 80-88, 2000.

MACHADO, R. O.; PIMENTA, T. Jr. A influência da responsabilidade social corporativa sobre o retorno das ações de empresas de capital aberto no Brasil. In: XXIV ENCONTRO NACIONAL DE ENGENHARIA DE PRODUÇÃO, Florianópolis, SC, Brasil, nov. de 2004.

MARCONI, M. A.; LAKATOS, E. M. Metodologia científica, 4. ed. São Paulo: Atlas, 2004.

MINISTÉRIO DA AGRICULTURA, PECUÁRIA E ABASTECIMENTO (MAPA). Disponível em: http://www.agricultura.gov.br/vegetal/culturas/cana-de-acucar. Acesso em 18. 01. 2012.

MONTEIRO, T. P. P.; FERREIRA, P. A. Gestão e meio ambiente: um estudo de caso em uma usina sucroalcooleira. In: Sociedade Brasileira de Economia Administração e Sociologia Rural (SOBER). Campo Grande, 25 a 28 de jul., 2009.

NASCIMENTO, L. F. Empresa psicopata versus empresa cidadã. Revista de Gestão Social e Ambiental (RGSA), v. 1, n. 1, p. 19-29, 2007.

PIACENT, E. A. Perspectivas do Brasil no mercado internacional de etanol. 2006. 173 p. Dissertação (Mestrado em Planejamento de Sistemas Energéticos) - Faculdade de Engenharia Mecânica, Universidade Estadual de Campinas, Campinas, 2006.

PROCANA. Disponível em: http://www.procana.com.br/ProCana/perfil setor.htm. Acesso em 19. 01.2012.

RAHMAN, M. N. A.; HERNADEWITA; DEROS, B. M.; ISMAIL, A. R. Cleaner production implementation towards environmental quality improvement. European Journal of Scientific Research, v. 30, n. 2, p.187-194, 2009.

SANCHES, C. S. Gestão Ambiental proativa. Revista de Administração de Empresas (RAE), v. 40 n. 01, p. 76-87, 2000.

SANTO, Z. N. E.; ALMEIDA, L. T. Etanol: impactos socioambientais de uma commodity em ascensão. In: VII ENCONTRO DA SOCIEDADE BRASILEIRA DE ECONOMIA ECOLÓGICA, Fortaleza, CE, nov. de 2007.

SEGATTO-MENDES, A. P.; LEMOS, D. H. Z. Resultados financeiros da inovação tecnológica para o aperfeiçoamento da gestão ambiental: o caso Sanepar. Revista de Administração (REAd), v. 13, n. 1, p. 01-23, 2007.

SILVA, L. D. d'Oliveira. Sustentabilidade do etanol brasileiro: uma proposta de princípios e critérios. 2010. 174 p. Dissertação de Mestrado apresentada ao Programa de Planejamento Energético, COPPE, da Universidade Federal do Rio de Janeiro, Rio de Janeiro, RJ, 2010.

SINDICATO DA INDÚSTRIA DE FABRICAÇ̃̃O DE AÇÚCAR E ETANOL DO ESTADO DE GOIÁS (SIFAEG). Disponível em: http://www.sifaeg.com.br/index.html Acesso em: 25. 01. 2012. 
SOUZA, C. B.; MIZIARA, F. Políticas de financiamento à expansão do setor sucroalcooleiro em Goiás versus políticas ambientais. In: VIII Congreso Latinoamericano de Sociologia Rural, Porto de Galinhas, PE, 2010.

UNIÃO DA INDÚSTRIA DE CANA-DE-AÇÚCAR (UNICA). Disponível em: http://www.unica.com.br/content/show.asp?cntCode $=\{0$ C8534A8-74A7-4952-8280C5F6FB9276B7\} Acesso em: 18. 01. 2012.

WALTON, S.V.; HANDFIELD, R. B.; MELNYK, S. A. The green supply chain: integrating suppliers into environmental management processes, International Journal of Purchasing and Materials Management, v. 34, n. 01, p. 2-11, 1998.

ZHU, Q; COTE, R. P. Integrating green supply chain management into an embryonic ecoindustrial development: a case study of the Guitang Group. Journal of Cleaner Production. v. 12, p. 1025-1035, 2004. 